\title{
The impact of the nodal status on the overall survival of non-surgical patients with esophageal squamous cell carcinoma
}

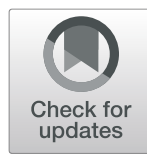

\author{
Zongxing Zhao ${ }^{1,2,3}$, Yanan Zhang ${ }^{4}$, Peiliang Wang ${ }^{1,2}$, Xin Wang ${ }^{2,5}$ and Minghuan $\mathrm{Li}^{2^{*}}$ (B)
}

\begin{abstract}
Background: The prognosis of $\mathrm{N}$ categories for patients with non-surgical esophageal carcinoma based on the number of metastatic lymph nodes is controversial. The present study analyzes prognostic implications of the number, extent, and size of metastatic lymph nodes for patients with esophageal squamous cell carcinoma (ESCC) treated with definitive (chemo-)radiotherapy to provide more information on treatment strategy.

Methods: We reviewed 357 ESCC patients treated with definitive radiotherapy between January 2013 and March 2016 retrospectively. We assessed potential associations between the involved extent (N0, 1 region, 2 regions, and 3 regions), number ( $\mathrm{NO}, 1-2,3-6$, and $\geq 7)$, and size $(\mathrm{NO}, \leq 2 \mathrm{~cm}$, and $>2 \mathrm{~cm}$ ) of metastatic lymph nodes and overall survival. Multivariate analyses of the clinicopathological factors were performed using the Cox proportional hazard model.

Results: 5 -year survival rates were $43.6 \%$ for patients in the No group and $29.3 \%$ in the $\mathrm{N}+$ group $(p=0.001)$. Kaplan-Meier analyses for all cases revealed that there were significant differences in survival based on the extent (the OS rates at 3 years were $53.3 \%$ for patients in the NO group, $45.7 \%$ in the 1 region-involved group, $28.0 \%$ in the 2 regions-involved group, and $13.3 \%$ in the 3 regions-involved group, $P<0.001$ ), number (the OS rates at 3 years were $49.0 \%$ for patients in the $1-2 \mathrm{LNs}$ group, $27.8 \%$ in the $3-6 \mathrm{LNs}$ group, 0 in the $\geq 7 \mathrm{LNs}$ group, $P<0.001$ ), and size (the OS rates at 3 years were $41.6 \%$ for patients in the $L N s \leq 2 \mathrm{~cm}$ group and $20.7 \%$ in the LNs $>2 \mathrm{~cm}$ group, $P=0.001$ ) of metastatic LNs. One hundred seventy-two patients (48.2\%) had experienced GTV failure, 157 (43.1\%) had distant failure, 49 (13.7\%) had out-of-GTV nodal failure, and 70 patients (19.6\%) had no evidence of disease at the last follow-up. Nodal status correlated statistically with GTV failure. Patients with LN metastases in the abdominal region had worse survival rates than those with metastases in the other regions. The extent and number of metastatic LNs, T category, Primary tumor location, and chemotherapy were independent prognostic factors of OS in multivariate analyses.
\end{abstract}

Conclusions: For patients with ESCC who received definitive (chemo-)radiotherapy, the number, extent, and size of metastatic LNs were prognostic factors, particularly of the T2/3 disease. Patients with LN metastases in the abdominal region had worse survival.

Keywords: Esophageal squamous cell cancer, Non-surgical, Metastatic lymph nodes, Definitive radiotherapy, Prognosis

\footnotetext{
* Correspondence: sdlmh2014@163.com

${ }^{2}$ Department of Radiation Oncology, Shandong Cancer Hospital and Institute,

Jinan, Shandong, China

Full list of author information is available at the end of the article
}

(c) The Author(s). 2019 Open Access This article is distributed under the terms of the Creative Commons Attribution 4.0 International License (http://creativecommons.org/licenses/by/4.0/), which permits unrestricted use, distribution, and reproduction in any medium, provided you give appropriate credit to the original author(s) and the source, provide a link to the Creative Commons license, and indicate if changes were made. The Creative Commons Public Domain Dedication waiver (http://creativecommons.org/publicdomain/zero/1.0/) applies to the data made available in this article, unless otherwise stated. 


\section{Background}

Esophageal carcinoma (EC) is a highly lethal disease. Of the two predominant histologic types, squamous cell carcinoma is the most common histological type in China, where it accounts for more than $90 \%$ of esophageal carcinoma cases [1]. Radiotherapy has been established as a definitive treatment for unresectable or medically inoperable tumors in ESCC patients. Chemotherapy has been added to the treatment and serves two purposes, including radiosensitization and control of micrometastatic diseases. Several randomized trials have demonstrated local control and survival benefit from chemoradiotherapy in patients with ESCC. There is advocacy for definitive chemoradiotherapy (dCRT) to serve as an alternative treatment for EC [2, 3]. Lymph node metastases are the most important factors affecting esophageal cancer prognosis $[4,5]$. However, increasing numbers of reports are showing that the $\mathrm{N}$-classification based on the number of metastatic lymph nodes (LNs) remains imperfect [6]. Some studies have shown that the extent of metastatic LNs could have significant prognostic implications for survival $[7,8]$.

Locoregional recurrence is reportedly more common after dCRT than after surgery [9]. However, there is little available information on how the status of metastatic lymph nodes influences prognosis for non-surgical patients with ESCC. In this study, we analyzed the prognostic implications of metastatic lymph nodes, including the factors of number, extent, and size, on the overall survival of ESCC patients who received definitive (chemo)radiotherapy.

\section{Material and methods Patients}

Between January 2013 and March 2016, 357 patients with histologically confirmed ESCC received definitive radiotherapy or chemoradiotherapy at Shandong Cancer Hospital Affiliated to Shandong University. The treatment strategies were made by a multidisciplinary team, including radiation oncologists, oncologists, and surgeons dedicated to thoracic malignancies. All patients underwent pretreatment staging workups, including tumor biopsy, esophagoscope, esophageal ultrasound (EUS), barium swallow, chest and abdominal computed tomography (CT), and/or fluorodeoxyglucosepositron emission tomography (FDG-PET) scan. A positive LN was defined by a short-axis length greater than $1 \mathrm{~cm}$ on CT or by a short-axis diameter of the paraesophageal, tracheoesophageal sulcus, pericardial angle, or abdominal LN greater than $5 \mathrm{~mm}$ [10]. LNs were considered to be positive when at least one of the following criteria was met: size $\geq 10$ $\mathrm{mm}$, round shape, hypoechoic pattern or clearly visible borders using EUS, or when the maximum standard uptake value (SUVmax) was higher than the background blood pool activity measured in the thoracic aorta or normal liver parenchymal activity. Patients were classified based on the extent (cervical, thoracic, and abdomen) of metastatic LNs (N0, 1 region, 2 regions, and 3 regions) according to the 8th edition of the AJCC staging system for ESCC. We only included patients with the T2, T3, and T4 diseases because the number of Tis-T1 that received radical radiotherapy or chemoradiotherapy was too small to be studied further. This study was approved by the medical ethics committees of the Shandong Cancer Hospital Affiliated to Shandong University, and informed consent was waived.

\section{Treatment}

A planned computed tomography scan was performed using an intravenous contrast with a slice thickness of $3 \mathrm{~mm}$. Each patient's images were transported to the treatment planning system to design the plan. FDG-PET was imported into the Eclipse Planning System (Varian Medical System, Palo Alto, CA) if needed. Radiotherapy was delivered using a dynamic multi-leaf linear accelerator with photon energies of $6 \mathrm{MV}$. The gross tumor volume (GTV) was defined as the visible macroscopic tumor and positive LNs based on all available clinical and imaging data. The clinical target volume (CTV) comprised the cranial and caudal margins of $3-5 \mathrm{~cm}$ and radial margins of $0.8-1.0 \mathrm{~cm}$ of a primary tumor and regional lymph node area at risk of microscopic disease. The planning target volumes were defined by $0.5-0.8 \mathrm{~cm}$ expansions of the CTV. Planning target volume (PTV) was delivered at a total dose of up to 50.4-66 Gy in 28-33 fractions (5 days a week, 5 to 6 weeks). Two hundred and twenty-seven patients received concurrent platinum-based chemotherapy with 5-fluorouracil or paclitaxel.

\section{Follow up}

Patients were followed-up every 3 months after treatment for the first 2 years, every 6 months for the next 3 years, and every 12 months after that. All patients underwent physical examinations, including barium swallow, cervical, chest, and abdominal enhanced CT scans, and endoscopy to assess recurrence or metastasis. When necessary, FDGPET was performed in response to specific symptoms. We assessed failure patterns on post-treatment images, including esophagogram, endoscopy, CT, or PET/CT scans. Patterns of failure were defined based on the sites of failure and included GTV (primary tumor and original LN) failure, out of GTV LN failure, and distant failure. The last general follow-up of survivors was done in January 2019. Overall survival (OS) was defined as the time from the date of pathologic diagnosis to the date of death. Surviving patients were censored on the day of the last contact.

\section{Statistical analysis}

Survival proportions were estimated using the Kaplan-Meier method. Multivariate and the univariate analyses were performed separately using the Cox proportional hazard model 
and log-rank test. A $p$-value of less than 0.05 was considered statistically significant. All statistical analyses were carried out using SPSS 23.0 (SPSS, Chicago, IL, USA).

\section{Results}

Clinical characteristics of the population and LNs

Complete data were available for 357 patients. The median follow-up was 27.8 months (range, 2-74 months), and the median age was 62 years (range, 43-83 years). Two hundred and twenty-seven of the 357 patients underwent chemoradiotherapy. Two hundred and sixty-three of the total patients had LN metastasis, with the median number of the involved LNs being 2 (range, 1-12). The median size of the involved LNs was $1.1 \mathrm{~cm}$ (range, 0.5$5.1 \mathrm{~cm})$. Of the 357 patients, the 1 region-involved $(48.2 \%$, 172 of 357) was the most common, followed by N0 (26.3\%, 94 of 357), 2 regions-involved (21.3\%, 76 of 357), and 3 regions-involved $(4.2 \%, 15$ of 357$)$. The detailed information is summarized in Table 1. The size of LNs correlated statistically with the $\mathrm{T}$ category, the number of LNs, and the extent of LNs $(P<0.001)$.

\section{Survival}

The 1-, 3-, and 5-year OS rates were 81.3, 42.6, and $33.2 \%$, respectively. The median survival time was 30.5 months for all patients. Survival rates for the N0 group were $90.2 \%$ at 1 year, $53.3 \%$ at 3 years, and $43.6 \%$ at 5 years, and the Median survival time was 46.0 months. Survival rates for the N+ group were $78.2 \%$ at 1 year, $38.8 \%$ at 3 years, and $29.3 \%$ at 5 years, and the Median survival time was 27.1 months. Survival rates in the N0 group were significantly better than those in the $\mathrm{N}+$ group ( $p=0.001$ Fig. 1 ).

At the time of the last follow-up contact, 172 patients (48.2\%) had experienced GTV failure, 157 (43.1\%) had distant failure, 49 (13.7\%) had out-of-GTV nodal failure, and 70 patients (19.6\%) had no evidence of disease. The risk of GTV failure by the different nodal size groups is shown in Table 2. After adjusting age, sex, treatment, and T-category according to the 8th AJCC system, multivariate analyses showed that there were significant differences in hazard ratios (HRs) for GTV failure between the 3-6 LNs group (HR, 2.445), $\geq 7 \mathrm{LNs}$ group (HR, 2.457), 2 regions-involved group (HR, 2.189), 3 regions-involved group (HR, 3.081), $\mathrm{LNs}>2 \mathrm{~cm}$ group (HR, 2.237), and N0 group (HR, 1). However, the HRs of other groups were similar to those of patients with N0 (HR, 1).

The Kaplan-Meier analyses for OS show that there were significant differences in survival based on the lymph node involved extent (N0, 1 region, 2 regions, and 3 regions, $P<0.001$ ), number (N0, $1-2,3-6$, and $\geq 7, P<0.001$ ), and size (N0, $\leq 2 \mathrm{~cm}$, and $>2 \mathrm{~cm}, P=0.001$ ). For 263 patients with metastatic LNs, the OS rates at 3 years were $49.0 \%$
Table 1 Patient characteristics and univariate analysis of prognostic factors

\begin{tabular}{|c|c|c|c|c|}
\hline Variables & $\begin{array}{l}\text { Number of } \\
\text { patients (\%) }\end{array}$ & $\begin{array}{l}\text { Median } \\
\text { survival (m) }\end{array}$ & $\begin{array}{l}\text { 3-y survival } \\
\text { rate (\%) }\end{array}$ & $P$ \\
\hline Age (years) & & & & 0.248 \\
\hline$<60$ & $105(29.4 \%)$ & 34.0 & $47.8 \%$ & \\
\hline$\geq 60$ & $252(70.6 \%)$ & 27.8 & $40.3 \%$ & \\
\hline Sex & & & & 0.377 \\
\hline Male & $282(79.0 \%)$ & 28.0 & $41.1 \%$ & \\
\hline Female & 75 (21.0\%) & 32.6 & $48.3 \%$ & \\
\hline Primary tumor location & & & & $<.001$ \\
\hline Upper & $168(47.1 \%)$ & 42.0 & $55.7 \%$ & \\
\hline Middle & $132(37.0 \%)$ & 26.0 & $35.4 \%$ & \\
\hline Lower & 57 (15.9\%) & 16.0 & $21.1 \%$ & \\
\hline T category & & & & $<.001$ \\
\hline $\mathrm{T} 2$ & $76(21.3 \%)$ & 49.0 & $59.2 \%$ & \\
\hline T3 & $217(60.8 \%)$ & 29.0 & $42.2 \%$ & \\
\hline T4 & $64(17.9 \%)$ & 17.5 & $24.3 \%$ & \\
\hline No. of LNs & & & & $<.001$ \\
\hline 0 & $94(26.3 \%)$ & 46.0 & $53.3 \%$ & \\
\hline $1-2$ & $150(42.0 \%)$ & 36.0 & $49.0 \%$ & \\
\hline $3-6$ & $96(26.9 \%)$ & 18.0 & $27.8 \%$ & \\
\hline$\geq 7$ & $17(4.8 \%)$ & 13.0 & 0 & \\
\hline Extent of LNs & & & & $<.001$ \\
\hline 0 & $94(26.3 \%)$ & 46.0 & $53.3 \%$ & \\
\hline 1 region & $172(48.2 \%)$ & 31.0 & $45.7 \%$ & \\
\hline 2 regions & $76(21.3 \%)$ & 19.0 & $28.0 \%$ & \\
\hline 3 regions & $15(4.2 \%)$ & 12.0 & $13.3 \%$ & \\
\hline Size of LNs & & & & 0.001 \\
\hline 0 & $94(26.3 \%)$ & 46.0 & $53.3 \%$ & \\
\hline$\leq 2 \mathrm{~cm}$ & $220(61.6 \%)$ & 28.0 & $41.6 \%$ & \\
\hline$>2 \mathrm{~cm}$ & $43(12.1 \%)$ & 17.0 & $20.7 \%$ & \\
\hline Treatment & & & & 0.010 \\
\hline CRT & $227(63.6 \%)$ & 33.8 & $47.6 \%$ & \\
\hline RT alone & 130 (36.4\%) & 25.6 & $33.7 \%$ & \\
\hline
\end{tabular}

LNs Lymph nodes, CRT Chemoradiotherapy, RT Chemoradiotherapy

for the 1-2 LNs group, $27.8 \%$ for the 3-6 LNs group and 0 for the $\geq 7 \mathrm{LNs}$ group based on the number, with corresponding median survival times of 36.0, 18.0 and 13.0 months, respectively. The OS rates at 3 years were $45.7 \%$ for the 1 region-involved group, $28.0 \%$ for the 2 regionsinvolved group and $13.3 \%$ for the 3 regions-involved group based on the extent, with corresponding median survival times of 31.0, 19.0 and 12.0 months, respectively. The OS rates at 3 years were $41.6 \%$ for the LNs $\leq 2 \mathrm{~cm}$ group and $20.7 \%$ for the LNs $>2 \mathrm{~cm}$ group based on the size, with corresponding median survival times of 28.0 and 17.0 months, respectively. 


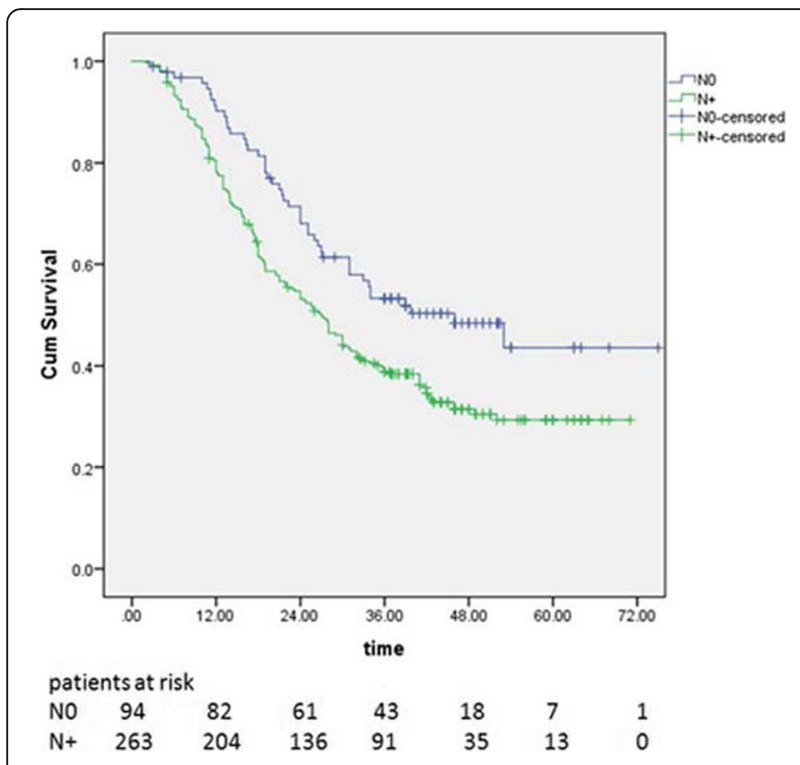

Fig. 1 Kaplan- Meier survival curves for patients based on the status of LNs

Table 3 lists the incidences of metastasis in different regions. The 3-year survival rates of patients with cervical region-involved, a thoracic region-involved only, and abdominal region-involved were 38.2, 43.4, and $16.2 \%$, respectively, and their median survival times were 28.0, 28.5, and 14.5 months, respectively. The KaplanMeier analyses show that there were significant differences in survival according to the different involved regions $(P<0.001$ Table 3$)$.

We performed analyses on patients in the $\mathrm{T} 2 / 3$ or $\mathrm{T} 4$ subgroups to explore the statuses of the LNs in predicting survival in different $\mathrm{T}$ categories. There were significant differences in survival in the T2/3 subgroup between patients based on the extent $(P<0.001$ Fig. $2 \mathrm{a})$, number $(P<$ 0.001 Fig. $2 \mathrm{c})$, and size ( $P=0.001$ Fig. $2 \mathrm{e})$ of metastatic

Table 2 Effect of nodal status on risk of GTV failure

\begin{tabular}{llll}
\hline Variables & Hazard Ratio & $95 \% \mathrm{Cl}$ & $P$ \\
\hline No. of LNs (baseline, N0) & & & 0.001 \\
$1-2$ & 1.025 & $0.684-1.538$ & 0.903 \\
$3-6$ & 2.445 & $1.627-3.672$ & 0.012 \\
$\geq 7$ & 2.457 & $1.222-4.941$ & 0.001 \\
Extent of LNs (baseline, N0) & & & 0.001 \\
$\quad 1$ region & 1.135 & $0.771-1.672$ & 0.521 \\
2 regions & 2.189 & $1.434-3.340$ & 0.001 \\
3 regions & 3.081 & $1.482-6.406$ & 0.002 \\
Size of LNs (baseline, N0) & & & 0.006 \\
$\quad \leq 2$ cm & 1.331 & $0.922-1.921$ & 0.127 \\
$\quad 2$ cm & 2.237 & $1.367-3.661$ & 0.001 \\
\hline GTV Gross tumor volume, Cl Confidence interval & &
\end{tabular}

GTV Gross tumor volume, Cl Confidence interval
Table 3 Overall survival of 357 patients based on the LNs Location

\begin{tabular}{lllll}
\hline & $\begin{array}{l}\text { No. of } \\
\text { Patients (\%) }\end{array}$ & $\begin{array}{l}\text { Median } \\
\text { Survival (m) }\end{array}$ & $\begin{array}{l}3-\text { Year } \\
\text { Survival (\%) }\end{array}$ & P Value \\
\hline No & $94(26.3 \%)$ & 46 & $53.3 \%$ & $<0.001$ \\
$\begin{array}{l}\text { Cervical region- } \\
\text { involved }\end{array}$ & $73(20.4 \%)$ & 28.0 & $38.2 \%$ & \\
$\begin{array}{l}\text { Thoracic region-only } \\
\text { Abdominal region- }\end{array}$ & $156(43.7 \%)$ & 28.5 & $43.4 \%$ & \\
involved & $51(14.3 \%)$ & 14.5 & $16.2 \%$ & \\
\hline
\end{tabular}

17 patients had both Cervical and Abdominal region-involved LNs LNs Lymph nodes

LNs. However, there were no significant differences between patients within the T4 stage (Fig. 2b, d, f) based on these factors.

Univariate and multivariate analyses of prognostic factors Univariate survival analyses showed that the $\mathrm{T}$ category, Primary tumor location, chemotherapy, and statuses of metastasis LNs were significantly associated with OS (Table 1). Table 4 presents the results of the multivariate analyses for OS. In the current study, the extent and number of metastatic LNs, T category, Primary tumor location, and concurrent chemotherapy were independent prognostic factors.

\section{Discussion}

The American Joint Committee on Cancer (AJCC) tumor node metastasis (TNM) cancer staging system has been used widely to guide treatment decision and evaluate prognosis. The 8th edition staging of esophageal carcinoma presents separate classifications for clinical (cTNM), pathologic (pTNM), and post-neoadjuvant (ypTNM) stage groups. Some studies suggest that both the number of metastatic LN station and the ratio of metastatic LN number to total harvested LN number are important prognostic factors. Mariette $\mathrm{C}$ et al. found that 5-year survival rates were significantly poorer for patients with a ratio of metastatic LNs (LNR) > 0.2 than survival rates for patients with a ratio of metastatic LNs (LNR) $\leq 0.2(22 \%$ vs. $54 \%, P<$ 0.001 ) [11]. 5-year survival rates in another study were 30 , 16 , and $13 \%$ for patients with $\mathrm{LNR} \leq 0.2,0.21-0.5$, and $>0.5$, respectively $(P<0.001)[12]$. However, these data provide little references to patients who received non-surgical treatment.

Clinical nodal staging is now also based on the number of metastatic LNs. Endosonographic-directed fine needle aspiration (EUS-FNA) is strongly recommended by the AJCC to confirm the histologic diagnosis of LNs for accurate clinical staging [13]. EUS-FNA is invasive and impracticable for patients with multiple LNs and is, therefore, not widely used in clinical practice. The FNA 


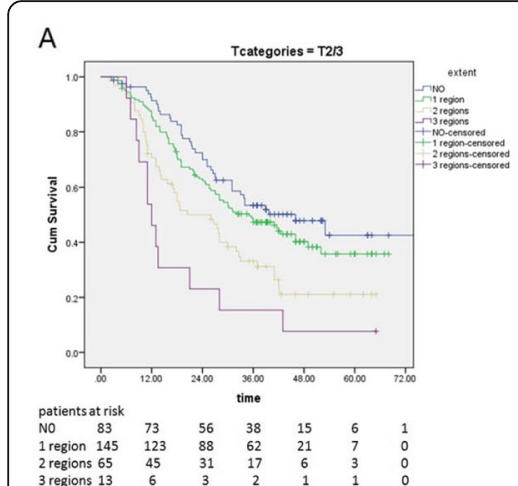

C

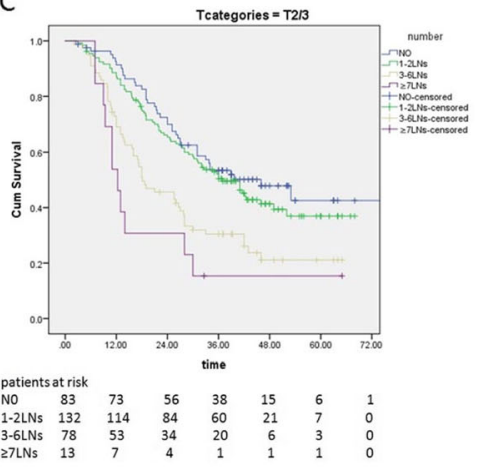

D

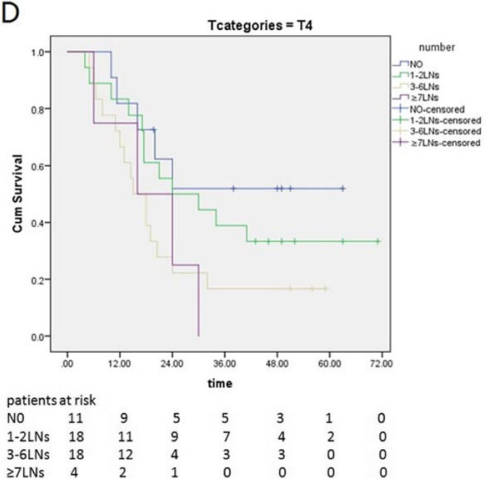

E

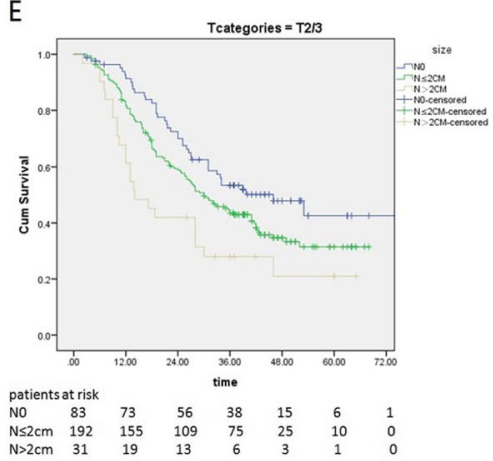

$\mathrm{F}$

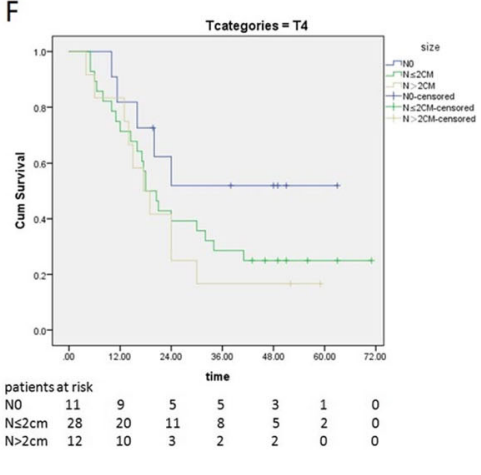

Fig. 2 Kaplan- Meier survival curves for patients based on the extent of metastatic LNs in the T2/3 subgroup (a) and the T4 subgroup (b) ( $p=$ 0.128 ), the number of metastatic LNs in the T2/3 subgroup (c) and the T4 subgroup (d) $(p=0.119)$, the size of metastatic LNs in the T2/3 subgroup (e) and the T4 subgroup (f) $(p=0.128)$

of peritumoral lymph nodes should be avoided because the needle would have to pass through the primary tumor in the esophageal wall, which could lead to a false-positive result [14]. EUS, CT, and FDG-PET afford regional lymph node imaging and are the principal noninvasive pretreatment staging workups. EUS is reportedly the most sensitive method for the detection of regional lymph node metastases, whereas CT and FDGPET have higher specificity [15]. Each imaging modality has its advantages and disadvantages; hence, CT, EUS, and PET should be considered complementary diagnostic methods. A recent study showed that the accuracy for $\mathrm{N}$ staging was $66 \%$ for EUS, $68 \%$ for PET, and $63 \%$ for CT [16], which is probably one of the reasons why prognostic implications for clinical categories will not be equivalent to those of pathologic categories. It is certainly worth analyzing the prognostic implications of metastatic LNs by using the information on their radiological features.

Our study indicates that the status of metastatic LNs, including the number, extent, and size, are prognostic factors for patients with ESCC who received radical radiotherapy. Per univariate analyses $(P<0.001)$, there were significant differences in survival based on the number of metastatic LNs according to the 8th edition of the AJCC staging system.
However, further subgroup analyses showed that survival in $\mathrm{N} 2$ and N3 patients did not differ $(p=0.181)$. Several previous studies that focused on operable ESCC also reported similar results. For example, Yamasaki et al. [17] and Chen et al. [18] recently revealed that there was no significant difference in survival between the N2 and N3 categories according to the AJCC TNM staging system in surgical patients. We also found that N0 versus N1 showed no significant difference in the survival of all cohort patients $(p=0.280)$. According to data for clinically staged patients from the Worldwide Esophageal Cancer Collaboration (WECC) by $\mathrm{T}$ W Rice et al., of 8156 clinically staged patients with squamous cell carcinoma, Non-risk-adjusted survival for ESCC was not distinctive for $\mathrm{cN} 0$ versus $\mathrm{cN} 1$ [6]. It is, therefore, necessary to determine the optimal cutoff points for the number of metastatic LN for prognosis in non-surgical patients. Several studies, for example, have reported significant differences in prognosis between patients with different metastatic lymph nodes (N0, 1-3, 24) $[11,19$, 20]. However, we found that significant differences in survival were observed overall and within each subgroup when patients were classified based on the extent of metastatic LNs involvement (N0, 1 region, 2 regions, and 3 regions). More emerging data are consistent with this result. Peng J et al. [7] and Ning et al. [8] proposed modified nodal categories 
Table 4 Multivariate Cox regression analysis of the prognostic factors for OS in patients with ESCC

\begin{tabular}{llll}
\hline Prognostic Factor & $\begin{array}{l}\text { Hazard } \\
\text { Ratio }\end{array}$ & $95 \% \mathrm{Cl}$ & $P$ \\
\hline Age $(<60$ vs $\geq 60)$ & 0.890 & $0.637-1.243$ & 0.495 \\
Sex (Male vs Female) & 0.722 & $0.503-1.304$ & 0.076 \\
Primary tumor location (baseline, Upper) & & & 0.010 \\
$\quad$ Middle & 1.292 & $0.948-1.761$ & 0.105 \\
$\quad$ Lower & 1.790 & $1.229-2.607$ & 0.002 \\
T category (baseline, T2) & & & 0.013 \\
$\quad$ T3 & 1.171 & $0.795-1.724$ & 0.425 \\
$\quad$ T4 & 1.827 & $1.162-2.872$ & 0.009 \\
No. of LNs (NO, $<3$ vs $\geq 3)$ & 1.667 & $1.177-2.361$ & 0.004 \\
Extent of LNs (baseline, N0) & & & 0.044 \\
$\quad 1$ region & 1.365 & $0.834-2.087$ & 0.125 \\
$\quad 2$ regions & 1.575 & $0.989-2.508$ & 0.056 \\
$\quad 3$ regions & 2.475 & $1.178-5.159$ & 0.016 \\
Size of LNs (NO, $\leq 2$ vs $>2$ cm) & 0.812 & $0.527-1.252$ & 0.347 \\
Treatment (CRT vs RT alone) & 0.569 & $0.425-0.762$ & 0.001 \\
\hline
\end{tabular}

LNs Lymph nodes, CI Confidence interval, CRT Chemoradiotherapy, $R T$ Radiotherapy

based on the number of metastatic LN stations for staging ESCC to discriminate the survival differences among groups better.

No previous evidence is available to prove that the size of metastatic LNs is of prognostic significance to OS or DFS. Our data showed that the size of the lymph node was significantly interrelated with extent and number. Therefore, the significant effect of size in predicting survival seen in univariate, but not in multivariate analyses, could be accounted for by the influence from extent and number. Also, the size of an LN was significantly interrelated with extranodal neoplastic spread (ENS). A previous report found ENS to be present in $27.2 \%$ of patients with nodes measuring $<2 \mathrm{~cm}, 55.8 \%$ of those with nodes measuring more than 3 to $4 \mathrm{~cm}$, and $100 \%$ of those with nodes measuring $>5 \mathrm{~cm}$ in head and neck cancers [21]. Because of the effect of ENS on prognosis and treatment [22], the size of a lymph node was still retained in the AJCC staging systems for head and neck carcinoma. In the present study, there were fewer patients with involved LNs greater than $2 \mathrm{~cm}$, which may have also affected the results of the analysis.

In our study, 172 patients (48.2\%) had experienced GTV failure, 157 (43.1\%) had distant failure, and 49 (13.7\%) had out-of-GTV nodal failure. Similar results were observed in a previous study by Zhang et al. who retrospectively assessed patients with locally advanced ESCC who had received IFI. With a median follow-up of 52.6 months, primary lesion and involved regional LN failure, distant metastasis, and initially, uninvolved LN failure were seen in $53.75,41.25$, and $30 \%$ of patients, respectively. The authors also found that there were no significant differences in OS for patients with and without initially, uninvolved LN failure [23]. The main pattern of regional recurrence was GTV failure in those with advanced-stage ESCC. Patients with $>6$ nodes, 3 regions-involved, and nodes $>2 \mathrm{~cm}$ in our study had a poor prognosis. We also found that the HRs for a GTV failure in these patients were higher than those in other groups. The OS rates at 3 years were 0 for the $\geq 7 \mathrm{LNs}$ group, $13.3 \%$ for the 3 regions-involved group, and $20.7 \%$ for the LNs $>2 \mathrm{~cm}$ group; the vast majority of patients were not curable. However, our study is retrospective. Further work needs to be done to establish whether non-surgical treatment should be delivered with curative intent to these patients.

For locally advanced ESCC, the primary tumor is the most important factor affecting survival. Li et al. retrospectively evaluated the failure patterns of 56 patients with clinical T4 M0 and found that 48 patients (85.7\%) had experienced failure: 39 (69.6\%) in-field, 7 (12.5\%) elective nodal, and 19 (33.9\%) distant, with only 1 patient (1.8\%) experiencing isolated elective nodal failure. The authors also found that there was no significant difference in the median OS of the patients with and without regional lymph node metastases ( 8 months vs. 7 months; $p=0.898$ ) [24]. For T4 stage, the predominant pattern after definitive CRT is a local failure, which is associated with worse overall survival $[25,26]$. The high local recurrence rate could have masked regional nodal failure because most of the patients died before their regional nodal failure. Perhaps this is the reason why the regional LN failure was not the main pattern of recurrence in these advanced stage ESCC patients. In the current study, we found that the nodal status, including number, extent, and size, had no significant influence on survival among patients with T4 stage, suggesting that we should pay more attention to primary tumors for patients with the T4 disease. When we develop treatment strategies, a limited radiation therapy target volume, such as Involved-field RT, rather than elective nodal irradiation, should be performed to minimize toxicity.

EC with abdominal nodal metastases is a strong predictor of poor outcome $[27,28]$. In the 6 th edition of the AJCC staging system, celiac LNs are defined as M1a stage in the lower third esophageal cancer and as M1b stage in the upper and middle third esophageal cancer [29]. However, the 7th AJCC staging system redefines celiac LNs as regional LNs [30]. This modification has proven to be controversial. Rutegard $\mathrm{M}$ et al. retrospectively analyzed 446 patients with distal esophageal cancer after resection and found that, compared to celiac nodenegative patients, celiac node-positive patients were at a $52 \%$ increased risk of disease-specific mortality [31]. The 
authors' view was that patients with distal esophageal cancer with celiac node metastasis seem to have similar poor survival to patients with more distant metastasis. For patients with celiac LNs metastasis receiving CRT, the celiac LNs metastasis group was found to have worse PFS and OS than the non-celiac LNs metastasis group [32]. In our study, the abdominal region included the station of paracardial, left gastric, common hepatic, splenic, and celiac nodes. The 3-year overall survival was $16.2 \%$ in the abdominal region involved, which had worse survival rates than those with metastases in the other regions. The prognostic value of abdominal LNs metastases, especially of celiac nodes, needs to be confirmed in large sample size, and it should be considered as a subcategory in staging systems.

There are some limitations to this study. First, our research was a retrospective study at a single institution, and the number of patients was relatively small, especially in the T1 and T4 subgroups. We need bigger data, including $\mathrm{T}$ stage, length, and multi-dimensional lymph node status to define the clinical staging of esophageal cancer, guide its treatment, and predict its prognosis. Secondly, we did not analyze the influence of histologic differentiation on prognosis because it would be obtained with difficulty in most patients confirmed by biopsy.

\section{Conclusions}

Apart from the primary tumor, we think that the LNs status, including number, extent, and size, should also be taken into account for prognostic implications for non-surgical patients with ESCC, rather than utilizing only one of them. These findings also provide further guidance for treatment strategy and the future staging system of EC. For selected patients with poor prognoses, such as those with $\geq 7 \mathrm{LNs}$, further research needs to be done to establish whether non-surgical treatment should be delivered with curative intent to these patients or not.

\section{Abbreviations \\ CT: Computed tomography; CTV: Clinical target volume; dCRT: Definitive chemoradiotherapy; EC: Esophageal carcinoma; ESCC: Esophageal squamous cell carcinoma; EUS: Endoscopic ultrasound; FDG-PET: Fluorodeoxyglucose- positron emission tomography; GTV: Gross tumor volume; HR: Hazard ratio; LNs: Lymph nodes; OS: Overall survival; PTV: Planning target volume; RT: Radiotherapy}

\section{Acknowledgments}

The authors thank all patients who participated in the present study.

\section{Authors' contributions}

ZZ and ML drafted the manuscript. YZ, PW and XW participated in data collection, and helped to analyze the data. All authors approved it for publication. All authors read and approved the final manuscript.

\section{Funding}

This research did not receive any specific grant from funding agencies in the public, commercial, or not-for-profit sectors.

\section{Availability of data and materials}

The datasets used and/or analysed during the current study are available from the corresponding author on reasonable request.

\section{Ethics approval and consent to participate}

This study was approved by the medical ethics committees of Shandong Cancer Hospital Affiliated to Shandong University and informed consent was waived.

\section{Consent for publication \\ Not applicable.}

\section{Competing interests}

The authors declare that they have no competing interests.

\section{Author details}

${ }^{1}$ School of Medicine, Shandong University, Jinan, Shandong, China. ${ }^{2}$ Department of Radiation Oncology, Shandong Cancer Hospital and Institute, Jinan, Shandong, China. ${ }^{3}$ Department of Radiation Oncology, Liaocheng People's Hospital, Liaocheng, Shandong, China. ${ }^{4}$ Department of Health Care, Liaocheng People's Hospital, Liaocheng, Shandong, China. ${ }^{5}$ Shandong First Medical University \& Shandong Academy of Medical Sciences, Jinan, Shandong, China.

Received: 25 April 2019 Accepted: 21 August 2019

Published online: 03 September 2019

\section{References}

1. Mei G, Yi-dian Z, Hai-jun Y, et al. Analysis of clinicopathological characteristics for 5406 cases of esophageal neoplasm. Chin J Cancer Prev Treat. 2008;15:54-6.

2. Herskovic A, Martz K, Al-Sarraf M, et al. Combined chemotherapy and radiotherapy compared with radiotherapy alone in patients with cancer of the esophagus. N Engl J Med. 1992;326(24):1593-8.

3. Cooper JS, Guo MD, Herskovic A, et al. Chemoradiotherapy of locally advanced esophageal cancer: long-term follow-up of a prospective randomized trial (RTOG 85-01). Radiation Therapy Oncology Group. JAMA. 1999;281:1623-7.

4. Rice TW, Ishwaran $\mathrm{H}$, Hofstetter WL, et al. Esophageal cancer: associations with (pN+) lymph node metastases. Ann Surg. 2017;265:122-9.

5. Chen J, Pan J, Zheng X, et al. Number and location of positive nodes, postoperative radiotherapy, and survival after esophagectomy with three field lymph node dissection for thoracic esophageal squamous cell carcinoma. Int J Radiat Oncol Biol Phys. 2012;82:475-82.

6. Rice TW, Apperson-Hansen C, DiPaola LM, et al. Worldwide esophageal cancer collaboration: clinical staging data. Dis Esophagus. 2016;29:707-14.

7. Peng J, Wang WP, Dong T, et al. Refining the nodal staging for esophageal squamous cell carcinoma based on lymph node stations. Ann Thorac Surg. 2016;101:280-6.

8. Ning ZH, Wang ZG, Chen J, et al. Proposed modification of nodal staging as an alternative to the seventh edition of the American Joint Committee on cancer tumor- node- metastasis staging system improves the prognostic prediction in the resected esophageal squamous cell carcinoma. J Thorac Oncol. 2015;10:1091-8.

9. Reid TD, Davies IL, Mason J, et al. Stage for stage comparison of recurrence patterns after definitive chemoradiotherapy or surgery for oesophageal carcinoma. Clin Oncol (R Coll Radiol). 2012;24:617-24.

10. Jun W, Yu JM, Zhang HZ. China nonoperative therapy of esophageal cancer clinical staging standard (draft). Chin J Radiat Oncol. 2010;19:179-80.

11. Mariette $\mathrm{C}$, Piessen $\mathrm{G}$, Briez $\mathrm{N}$, et al. The number of metastatic lymph nodes and the ratio between metastatic and examined lymph nodes are independent prognostic factors in esophageal cancer regardless of neoadjuvant chemoradiation or lymphadenectomy extent. Ann Surg. 2008; 247(2):365-71.

12. Greenstein AJ, Litle VR, Swanson SJ, et al. Prognostic significance of the number of lymph node metastases in esophageal cancer. J Am Coll Surg. 2008;206:239-46.

13. Rice TW, Kelsen DP, Blackstone EH, et al. Esophagus and esophagogastric junction. In: Amin MB, Edge SB, Greene FL, et al., editors. AJCC cancer staging manual. 8th ed. New York: Springer; 2017. p. 185-202. 
14. Plukker JT, van Westreenen HL. Staging in oesophageal cancer. Best Pract Res Clin Gastroenterol. 2006;20(5):877-91.

15. van Vliet EP, Heijenbrok-Kal MH, Hunink MG, et al. Staging investigations for oesophageal cancer: a meta-analysis. Br J Cancer. 2008;98(3):547-57.

16. Choi J, Kim SG, Kim JS, et al. Comparison of endoscopic ultrasonography (EUS), positron emission tomography (PET), and computed tomography (CT) in the preoperative locoregional staging of resectable esophageal cancer. Surg Endosc. 2010;24(6):1380-6.

17. Yamasaki M, Miyata $\mathrm{H}$, Miyazaki Y, et al. Evaluation of the nodal status in the 7th edition of the UICC-TNM classification for esophageal squamous cell carcinoma: proposed modifications for improved survival stratification: impact of lymph node metastases on overall survival after esophagectomy. Ann Surg Oncol. 2014;21:2850-6.

18. Chen SB, Weng HR, Wang G, et al. Prognostic factors and outcome for patients with esophageal squamous cell carcinoma underwent surgical resection alone: evaluation of the seventh edition of the American Joint Committee on cancer staging system for esophageal squamous cell carcinoma. J Thorac Oncol. 2013;8:495-501.

19. Bollschweiler E, Baldus SE, Schröder W, Schneider PM, Hölscher AH. Staging of esophageal carcinoma: length of tumor and number of involved regional lymph nodes. Are these independent prognostic factors? I Surg Oncol. 2006:94:355-63.

20. Kunisaki C, Akiyama $H$, Nomura $M$, et al. Developing an appropriate staging system for esophageal carcinoma. J Am Coll Surg. 2005;201:884-90.

21. Mao YP, Liang SB, Liu LZ, et al. The N staging system in nasopharyngeal carcinoma with radiation therapy oncology group guidelines for lymph node levels based on magnetic resonance imaging. Clin Cancer Res. 2008; 14(22):7497-503.

22. Greenberg JS, Fowler R, Gomez J, et al. Extent of extracapsular spread : a critical prognosticator in oral tongue cancer. Cancer. 2003;97(6):1464-70.

23. Zhang $X$, Li M, Meng $X$, et al. Involved-field irradiation in definitive chemoradiotherapy for locally advanced esophageal squamous cell carcinoma. Radiat Oncol. 2014;9(1):64-70.

24. Li M, Zhao F, Zhang $X$, et al. Involved-field irradiation in definitive chemoradiotherapy for T4 squamous cell carcinoma of the esophagus. Curr Oncol. 2016;23(2):131-7.

25. Amini A, Ajani J, Komaki R, et al. Factors associated with local-regional failure after definitive chemoradiation for locally advanced esophageal cancer. Ann Surg Oncol. 2014;21:306-14.

26. Ishihara $\mathrm{R}$, Yamamoto $\mathrm{S}$, lishi $\mathrm{H}$, et al. Factors predictive of tumor recurrence and survival after initial complete response of esophageal squamous cell carcinoma to definitive chemoradiotherapy. Int J Radiat Oncol Biol Phys. 2010;76:123-9.

27. Trovo M, Bradley J, El Naqa I, et al. Esophageal carcinoma with celiac nodal metastases; curative or palliative? J Thorac Oncol. 2008;3(7):751-5.

28. Heidemann J, Schilling MK, Schmassmann A, et al. Accuracy of endoscopic ultrasonography in preoperative staging of esophageal carcinoma. Dig Surg. 2000;17(3):219-24.

29. Frederick LG, Fleming ID, Fritz AG, Balch CM, Haller DG, Morrow M. AJCC cancer staging manual. New York: Springer-Verlag; 2002.

30. Edge S, Compton CC, Fritz AG, Greene FL, Trotti A. AJCC cancer staging manual. New York: Springer-Verlag; 2010. p. 7.

31. Rutegard M, Lagergren $P$, Johar $A$, et al. The prognostic role of coeliac node metastasis after resection for distal oesophageal cancer. Sci Rep. 2017;7: 43744.

32. Chen YH, Lu H, Wang YM, et al. The prognostic significance of celiac lymph node metastasis in patients with locally advanced esophageal squamous cell carcinoma receiving curative concurrent chemoradiotherapy. Oncotarget. 2017;8(56):96190-202.

\section{Publisher's Note}

Springer Nature remains neutral with regard to jurisdictional claims in published maps and institutional affiliations.

Ready to submit your research? Choose BMC and benefit from:

- fast, convenient online submission

- thorough peer review by experienced researchers in your field

- rapid publication on acceptance

- support for research data, including large and complex data types

- gold Open Access which fosters wider collaboration and increased citations

- maximum visibility for your research: over $100 \mathrm{M}$ website views per year

At BMC, research is always in progress.

Learn more biomedcentral.com/submissions 